\title{
Evaluating Search Methods for Identifying Candidates for Novel Biologically Inspired Sunscreens
}

\author{
Irene Shen ${ }^{1}$ and Thomas Hesselberg\# \\ ${ }^{1}$ Shanghai High School International Division, Shanghai, China \\ \#Advisor
}

$\underline{\text { ABSTRACT }}$

As the Earth's ozone layer, which blocks harmful UV radiation from reaching Earth's surface, becomes thinner, sunscreens have become one the most used and most important cosmetic products in recent decades. However, UV filters (both organic and inorganic) in the current synthetic sunscreen are found to affect the marine ecosystem negatively. They pollute the marine environment and cause damage to organisms 'reproductive and digestive systems (from microorganisms to mammals). Here, we use biologically inspired design with a problem and sustainability-driven approach to identify possible plant or animal-inspired ingredients that could be extracted and used to obtain high protection from the sun while minimizing toxicity to human skin and pollution of the marine environment. We used Google, Google Scholar and AskNature to identify solutions and evaluate their effectiveness. While the three search methods did not differ statistically in the number of initially solutions found, Google was perhaps surprisingly the one that generated most hits. However, in terms of the most promising solutions, AskNature generated the most.We identified nine solutions with a particular high potential based on their UV absorption and potential for mass production for further development: raspberry seed oil, nanoparticles of ivy rootlets, cuticular wax of dwarf mountain pine, lichen extract, MAAs from cyanobacteria, MAAs from dinoflagellates, red sweat of hippopotamus, mucus from mushroom coral, and gadusol compound from marine organisms of which we found that nanoparticles of ivy rootlets, lichen extracts and gadusol to be especially promising.

\section{Introduction}

Sunlight is one of the most essential elements required to sustain the growth of all life on Earth. Plants need sunlight for photosynthesis, the process of using sunlight to generate food from carbon dioxide and water (Lambers et al. 2008), and animals need sunlight for vitamin $\mathrm{D}$, which regulates calcium and phosphate level in the body and contributes to the health of bones, teeth, and muscles. However, excessive exposure to UV radiation may lead to sunburn, actinic keratosis, and melanoma (Dummer et al. 2002). Although tanning, or the darkening of skin color that results from the increasing production of melanocytes and melanosome (Park et al. 2009), is one mechanism that protects humans from UV radiation, it occurs post-exposure with substantial delay before effective protection is achieved. Hence, sunscreens are used to prevent damage from over exposure to UV radiation. Organic (chemical) and inorganic (mineral) UV filters, are the key components in sunscreens; they absorb across the UV-A (400-315nm) and UV-B (315-280nm) regions (lewis et al. 2017) which allows them to effectively protect the human skin. Benzophenone-3 (BP-3) and 4methylbenzylidene $(4 \mathrm{MBC})$ are the two most common organic (or chemical) UV filters while titanium dioxide $\left(\mathrm{TiO}_{2}\right)$ and zinc oxide $(\mathrm{ZnO})$ are the two most common inorganic (or mineral) UV filters (see Table 1). As Earth's ozone layer, which blocks harmful UV rays from reaching Earth's surface, becomes thinner, and as tanning becomes a beauty trend in western societies, sunscreens have now become one of the most used cosmetic products. The market value has reached 8500 million dollars in 2019, and is estimated to hit 10800 million dollars by 2024 (Ridder et al. 2020). However, the UV filters used in sunscreens are found to be a significant pollutant of marine ecosystems. As coastal tourism has become popular in recent decades, total UV filter remains washed off from beachgoers at a Mediterranean 
beach was estimated to be 5.2 grams per person per day during peak season (Labille et al. 2020). The UV filter remains are found to damage the DNA of coral reefs (Downs et al. 2016), disrupt the reproduction system of Japanese rice fish (Kim et al. 2014), negatively affect the growth of phytoplankton, fuel the growth of algae that block sunlight from reaching organisms under the water. (Tovar-Sánchez et al. 2013), and are found to remain in liver tissues of dolphins (Gago-Ferrero et al. 2013). In this study, we employ a problem and sustainability driven approach and aim to identify possible solutions for new biologically inspired sunscreens with high SPF (sun protection factor) that simultaneously minimize the toxicity to human skin and pollution of the marine environment. The SPF is the proportion of sun radiation that would reach the skin after applying the sunscreen (Baker et al. 2017), and it is calculated by taking into account the erythema action spectrum (the ability of producing erythema - i.e., redness/sunburn - on human skin under a specific wavelength), the sun's radiation power, how much radiation is absorbed, and the ability of the skin to be damaged (Gao et al. 2011). Biological inspired designs (BID) mimics or are inspired by living organisms. BID can be categorized as problem-driven, solution driven, or sustainability driven (Lenau et al. 2018). The problem driven (or top-down) approach starts with a problem and aims to identify possible solutions in nature. The solution-driven (or bottom-up) approach starts with analyzing a compelling biological phenomenon and later aims to identify technological areas where the solution can be applied. The sustainability driven approach can include either problem or solution driven methods, but it focuses on the sustainability angle when solving problems (i.e. nature using fully recyclable materials created under ambient conditions). The sustainability and problem driven approach that this study employs focused on environmental sustainability and is dedicated to find solutions that are plant, microorganism, and animal inspired. Several herbal extracts and lichens are found to have a high SPF values which could potentially be applied in future sunscreens (Radice et al. 2016). Similarly, many marine organisms use compounds and acids like the gadusol compound, and mycosporine-like amino acid (MAA), for their UV protecting ability (Shick et al. 2002). These have been suggested as potential candidates to replace synthetic UV filters (Osborn et al. 2015).

Table 1. Structures of common synthetic UV filters. Structures generated using King Draw.

\begin{tabular}{|c|c|c|}
\hline Common organic UV Filters & Benzophenone-3 (BP-3) & 4-methylbenzylidene (4MBC) \\
\hline Common inorganic UV Filters & $\begin{array}{l}\mathrm{O}^{\mathrm{Zn}} \\
\text { Formula:OZn } \\
\text { Exact Mass:79.92 } \\
\text { Mol.Wt.:81.38 } \\
\text { zinc oxide }(\mathrm{ZnO})\end{array}$ & $\begin{array}{l}\text { Formula: } \mathrm{O}_{2} \mathrm{Ti} \\
\text { Exact Mass:79.94 } \\
\text { Mol.Wt.:79.86 } \\
\text { Titanium dioxide }\left(\mathrm{TiO}_{2}\right)\end{array}$ \\
\hline
\end{tabular}

Not all UV absorbing compounds have potential to be effective UV sunscreens. A solution or compound is only considered when the component absorbs UV radiation across the UV-A and UV-B regions with a high absorption coefficient and when it is able to sustain enough concentration that it effectively reduces a sufficient amount of received UV radiation (Gao et al. 2011). The main components in a bottle of sunscreen are water, thickening agents, UV filter, emollients, and emulsifiers (Baker et al. 2017). Water in sunscreens makes up about 60-80\% of the volume, while the thickening agents makes up about $2 \%$. UV filters makes up about $10-20 \%$, while emollients and emulsifiers 
make up about $20 \%$ of a sunscreen's volume (Baker et al. 2017). The current synthetic (or commercial) sunscreens are successful at providing protection for human. However, they not only negatively affect the marine environment, but are also likely to have adverse effects on human health. Although, there are no concrete evidence that the current UV filters represent a significant health damage to humans, there are cases of allergies (rashes and redness on skin) caused by UV filters and plausible speculations made suggesting the synthetic UV filters in sunscreen may disrupt the body's normal hormone level (Labille et al. 2020). Concerns over possible adverse effects that the chemical UV filters may have on the human skin are referred to as the "sunscreen controversy" (Baker et al. 2017). These concerns towards the current synthetic sunscreens act as an incentive for developing natural sunscreens that are environmentally sustainable and safe for human use. In this paper, we aim to identify nine natural UV radiation absorbing components produced or extracted by plants, microorganisms, and animals found by reviewing journal articles or hits generated by Google, Google scholar, and AskNature, which we deem have the highest potential for replacing current synthetic UV filters. We ask two main research questions: 1, Which of the three search engines we used (Google, Google Scholar and AskNature) generate identifies the most useful and practical candidates? 2. Which 3 plants, 3 microorganisms, and 3 animals have the highest potential for developing biologically inspired UV filters that are potentially applicable on human skin? In addition, we ask if they are extractable and can be mass produced?

\section{Materials and Methods}

The present review was created utilizing the following search engines and databases: Google, Google Scholar, and AskNature. The following search terms were entered in Google: "Natural protection from the sun in plants," "Natural protection from the sun in microorganisms,"and "Natural protection from the sun in animals." The first 20 Web pages that appeared for each search term were selected, and web pages relevant to natural sunscreens produced by plants, microorganisms, and animals were reviewed. The following search terms were entered in Google scholar: "Natural protection from the sun and UV filters in plants," "Natural protection from the sun and UV filters in microorganisms," and "Natural protection from the sun and UV filters in animals." The first 20 journal articles that appeared for each search term were selected, and journal articles focussing on compounds produced by plants, microorganisms, and animals that provide UV protection were reviewed. The following search terms were entered in AskNature: "protect from sunlight," "protect from UV radiation", and "Natural UV filters." The first 20 journal articles that appeared were selected; strategies and their references related to natural extracts from plants, microorganisms, and animals with UV absorbing ability were reviewed. We identified the following search words: sunscreens, natural, marine environment, pollution, UV filters, and toxicity. Journal articles or webpages containing none of the identified words were eliminated, as where those that we considered irrelevant to our aim of discovering possible plant or animal-inspired ingredients that could be extracted and obtain high protection from the UV radiation while minimizing toxicity to human skin and pollution to the marine environment. Papers deemed irrelevant were those that focused on the development of current synthetic UV filters, and on natural products with no UV protecting ability. Each accepted paper was analyzed, and three potential plant-based ingredients, three microorganism-based ingredient, and three animal-inspired ingredients that are possible to replace current synthetic UV filters were selected for a more in-depth analysis. The number of hits generated by the different search engines were compared statistically with a chi-square test using a significance level of 0.05 .

\section{Results}

\section{Result for search engines}

Google, Google Scholar, and AskNature, were used to compile resources. Each search engine was assigned 3 search terms, and the first 20 hits generated from each search term were reviewed (Fig. 1). For Google, 40 hits (unique websites) were identified, while 23 journal articles were identified through Google Scholar and AskNature, generated 
26 ideas from the 3 search terms. This difference suggests that Google rather surprisingly generates the most useful ideas, although we found no statistically significant difference between the search methods for the initial idea generation phase (Chi-square test: $\chi^{2}=5.55, \mathrm{df}=2, \mathrm{P}=0.062$ ). However, when we compare the methods for the 9 solutions that we analyzed in detail (Table 2), then AskNature (6/9) found the most solutions followed by Google (4/9) and Google Scholar (3/9). Only one potential solution, MAAs from cyanobacteria, was found by all 3 search methods (Table 2).

\section{Raspberry seed oil}

Natural oils like raspberry seed oil, coconut oil, and carrot seed oil are found to have an UV absorbing ability. Raspberry seed oil, being the highest, is identified to have a SPF value of 28-50 (Oomah et al. 2000). Raspberry seed have always been wasted as a byproduct when producing raspberry juice. It is estimated that 312 thousand tonnes of raspberries are produced globally per year, and almost all are used to produce raspberry juice. The amount of oil that could be produced from the left over raspberry seed is estimated to be about 400 tonnes. Unprocessed raspberry seed oil has an absorption ability across all UV regions mainly through scattering UV radiation (Oomah et al. 2000). However, the surprisingly high SPF value of raspberry seed oil is disputed. A recent study found a SPF value of raspberry seed oil of only 2.6 0.5 through SPF determination (the process of measuring a substance's SPF value) operated within a raspberry plant (Ácsová et al. 2021).

\section{Nanoparticles of ivy rootlets}

Nanoparticles from ivy (Hedera helix) rootlets were isolated using a tissue culture method and measured to have a diameter of $65.3 \pm 8.04 \mathrm{~nm}$ (Xia et al. 2010). The tissue culture method grows roots in sterile magenta GA-7 to maximize the production of root hairs that contains the nanoparticles while preventing possible contamination (Lenaghan et al. 2013). The nanoparticle was compared with $\mathrm{TiO}_{2}$, one of the most common inorganic UV filters, on UV absorbing or scattering ability, toxicity level to mammal cells, biodegradability, and the ability to diffuse through human skin. The optical extinction-level or the absorption rate that causes energy loss (Lebedev et al. 1999) and UV radiation across the UV-B region of the nanoparticles extracted from ivy rootlets outperforms $\mathrm{TiO}_{2}$ massively. The toxicity level measured using HeLa cells (human cells line used to test toxicity level of nanoparticles) is found to have negligible toxicity which is significantly lower than $\mathrm{TiO}_{2}$ (Xia et al. 2010). The nanoparticles are degradable when modeled with the human enzymatic digestion process. The nanoparticles are completely degraded after exposure to Proteinase $\mathrm{K}$ for 30 minutes. The nanoparticles are also predicted to have little risk of skin penetration (Xia et al. 2010), and high potential to be mass produced using a tissue culture method that produces root hairs that generate the ivy nanoparticles in relatively large amounts (Lenaghan et al. 2013). Compiling all the factors, nanoparticles of ivy rootlets have a significant potential for being applied in sunscreens in the future.

\section{Cuticular wax of dwarf mountain pine}

The dwarf mountain pine (Pines mugo) is primarily found at high altitudes with a constant exposure to high UV radiation due to the thinner atmosphere. It uses epicuticular wax as a protection mechanism, where chromophores in the cuticular wax are found to have UV absorbing ability across the UV-A and UV-B spectrum (Jacobs et al. 2007). Absorbance of the cuticular wax in dwarf mountain pine showed correlation with their altitude level: the absorbance of the cuticular wax of dwarf mountain pines grown in the botanical garden at sea level is lower in the UV-B range when compared to wild populations growing in the Alps (Jacobs et al. 2007). This correlation indirectly demonstrates and accentuates the Cuticular wax as a UV defense mechanism established by the Dwarf Mountain pine. Although the UV absorbing ability of the cuticular wax of Dwarf Mountain pine is confirmed, its potential to replace current UV-filters need to be further evaluated. 


\section{Lichen extracts (Usnic acid)}

Four Chilean lichens: Erioderma leylandii, Xanthoparmelia farinosa, Coelopogon epiphorellus, and Pseudocyphellaria bereberina contain usnic acid that has been identified as a UV absorber and antioxidant. Experiments were conducted on volunteers, and the SPF value measured as 4.2 (Radice et al. 2016). Usnic acid exhibits the highest absorbing ability in the UV-B spectrum (Radice et al. 2016). The SPF value of a naturally extracted value is comparable to a type of Nivea carotene oil spray with a labeled SPF value of 6 . Although usnic acid is one of the best natural filters extracted from plants that exhibits the highest SPF value, the protection is still limited. Modifications or testing is required before usnic acid could have the potential to replace current synthetic sunscreens.

\section{MAAs from cyanobacterias}

MAAs, or mycosporine-like amino acids, are produced mostly by marine microorganisms that occur in environments that are highly exposed to UV-radiation. Cyanobacterias represent a large group of bacterias consisting different forms of MAAs with slightly varying UV-absorbance spectrum at different wavelengths. MAAs in cyanobaterial lichens (Mycosporine-glycine) are found to have a maximum UV absorbing ability at 309-310nm (Shick et al. 2002). MAAs in terrestrial cyanobacterium (Nostoc commune) performs a UV-absorbing ability at the UV-A spectrum (334 nm and $332 \mathrm{~nm}$ ) (Matsui et al. 2011; Nazifi et al. 2012). In addition to their UV absorbing ability, MAAs from cyanobacterias also effectively block thymine dimer, which is a possible leading factor in developing skin cancer (Oyamada et al. 2008). MAAs from cyanobacterias could potentially replace current synthetic UV filters due to their outstanding UV absorbing ability in the UV-A part of the spectrum, their ability to block thymine dimer, and the potential for them to be mass produced as two bio synthesis pathway or methods of MAAs from cyanobacterias are discovered in Anabaena variabilis (Derikvand et al. 2017).

\section{MAAs from dinoflagellate}

Dinoflagellates belongs to the protists kingdom, and the MAAs within are slightly different from the ones in cyanobacterias. Dinoflagellates, when exposed to PAR (photosynthetically available radiation), are able to accumulate MAAs in high densities (Shick et al. 2002). However, the cellular MAAs content did not change with variation of radiations (PAR and UVR). The MAAs content within dinoflagellate follows a predictable pattern independent from cell volume and chlorophyll showing some form of stability (Taira et al. 2004). However, there are no specific indicators of the UV absorbing ability from MAAs in dinoflagellates, although it is likely to be similar to MAAs from cyanobacteria described above. More experiments and investigations are required before considering it as becoming a potential commercial UV filter.

\section{Red sweat of Hippopotamus}

The hippopotamus (Hippopotamus amphibius) is a large African mammal that lives in and around rivers and as such, it is constantly exposed to sunlight and UV radiation. Without having physical protection from the UV radiation (i.e. no fur), the hippopotamus has developed its own chemical protection: red sweat. The hippopotamus secretes a colored sweat with a red (hipposudoric acid) and orange pigment (norhipposudoric acid). The pigments provide antibiotics and UV protection across the UVA and UVB regions (Galasso et al. 2009). The specific SPF value of the pigments has not been estimated, and the process of obtaining the pigments from the hippopotamus are complicated. However; it is potentially possible to synthesize the pigments chemically and thus it might be mass produced in the future (Saikawa et al. 2004). 


\section{Gadusol compound from Marine organisms}

Gadusol compounds have a similar structure to MAAs and are found to have a UV absorbing ability at the UV-A spectrum (Osborn et al. 2019). Recent studies have identified the presence of gadusol compounds in the eggs of European sea bass (Dicentrarchus labrax) and found it able to be synthesized by 2-epi-5-epi valiolone (EEVS), and methyltransferase-oxidoreductase (MT-Ox) (Osborn et al. 2019). The gadusol compound synthesized are found to have different absorption level at different $\mathrm{pH}$ values. At a neutral $\mathrm{pH}$ value of 7.0 (close to human skin), the gadusol compounds have UV-absorbance at 296nm (Osborn et al. 2019). The gadusol compounds show a high potential to be synthesized and mass produced using a genetic mix and matched approach using genes from zebrafish and Gram- $(+)$ bacteria (Osborn et al. 2019). Gadusol compounds therefore have significant potential to replace current synthetic UV filters due to their unique UV absorbing ability at the UV-A and UV-B spectrum, and their potential for mass production.

\section{Mucus from mushroom coral}

Mushroom corals secrete mucus (Fungi funguses) that are found to have a UV-absrobing ability. Fungi funguses is chosen because it could adapt to the environment in the laboratory, and it could produce a high amount of mucus (Krupp et al. 1982). The concentration of the secreted UV absorbing mucus, likely to contain MAAs, positively correlates with the weight of the coral and negatively correlates with the depth below sea level that the coral habitats at. The absorbance spectrum of the mucus covers the UV-A and UV-B regions ranging from 290-360 nm and peaking at $332 \mathrm{~nm}$. However, the concentration of UV-absorbing compounds in the mucus is unstable as it reaches a maximum 2 minutes after secretion and decreases subsequently (Drollet et al. 1993). Although the UV absorbing ability of the mucus secreted by mushroom corals is confirmed, it is very unstable and there is currently no evidence that is has potential to be mass-produced.

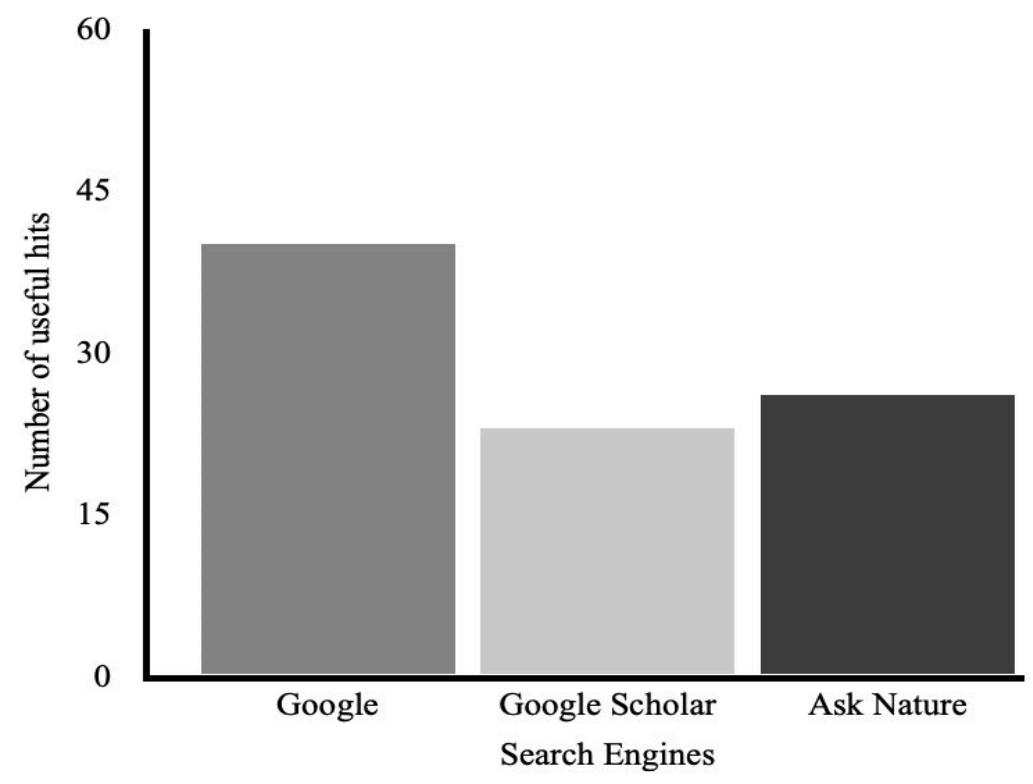

Figure 1. Total number of useful hits generated by each search engine (Google, Google Scholar, and Ask nature) with three search terms. Google: (search terms: "Natural protection from the sun in plants," "Natural protection from the sun in microorganisms," and "Natural protection from the sun in animals"), Google Scholar: (search terms: 
"Natural protection from the sun and UV filters in plants," "Natural protection from the sun and UV filters in microorganisms," and "Natural protection from the sun and UV filters in animals"), and Ask Nature: (search terms: "protect from sunlight," "protect from UV radiation", and "Natural UV filters").

Table 2. Summary table of the nine identified potential UV-filters.

\begin{tabular}{|c|c|c|c|c|}
\hline & SPF & $\begin{array}{l}\text { Wavelength of max- } \\
\text { imum UV absorp- } \\
\text { tion level (nm) }\end{array}$ & $\begin{array}{l}\text { Potential ways for } \\
\text { mass production }\end{array}$ & Search engine \\
\hline Raspberry seed oil & $\begin{array}{l}28-50 \text { (Oomah et al. } \\
2000 \text { ) } \\
2.6 \pm 0.5 \text { (Ácsová et } \\
\text { al. } 2021 \text { ) }\end{array}$ & Not specified & $\begin{array}{l}\text { Released as a by- } \\
\text { product when pro- } \\
\text { ducing raspberry } \\
\text { juice }\end{array}$ & Google \\
\hline $\begin{array}{l}\text { Nanoparticle of Ivy } \\
\text { rootlet }\end{array}$ & Not identified & Not specified & $\begin{array}{l}\text { Tissue culture } \\
\text { method (Lenaghan et } \\
\text { al. 2013) (Xia et al. } \\
\text { 2010) }\end{array}$ & AskNature \\
\hline $\begin{array}{l}\text { Cuticular wax of } \\
\text { dwarf mountain } \\
\text { pine }\end{array}$ & Not identified & $\begin{array}{l}\text { Extinction at } 309 \mathrm{~nm} \\
\text { Emission at } 403 \mathrm{~nm} \\
\text { (Jacobs et al. 2007) }\end{array}$ & Not identified & AskNature \\
\hline Lichen extracts & $\begin{array}{l}\text { Usnic acid: } 4.2 \\
\text { (Radice et al. 2016) }\end{array}$ & Not specified & Not identified & Google scholar \\
\hline $\begin{array}{l}\text { MAAs from cyano- } \\
\text { bacterias }\end{array}$ & Not identified & $\begin{array}{l}\text { 1) cyanobaterial } \\
\text { lichens (Mycospor- } \\
\text { ine-glycine): 309- } \\
\text { 310nm (Shick et al. } \\
\text { 2002). } \\
\text { 2) terrestrial cyano- } \\
\text { bacterium (Nostoc } \\
\text { commune): } 334 \text { and } \\
332 \text { (Matsui et } \\
\text { al. 2011; Nazifi et al. } \\
\text { 2012). }\end{array}$ & $\begin{array}{l}\text { Identified a two bio } \\
\text { synthesis pathway in } \\
\text { Anabaena variabilis } \\
\text { (Derikvand et al. } \\
\text { 2017). }\end{array}$ & $\begin{array}{l}\text { Google, Google } \\
\text { Scholar, and } \\
\text { AskNature }\end{array}$ \\
\hline $\begin{array}{l}\text { MAAs from dino- } \\
\text { flagellate }\end{array}$ & Not identified & $\begin{array}{l}310 \text { and } 334 \mathrm{~nm} \\
\text { (Taira et al. 2004). }\end{array}$ & Not identified & $\begin{array}{l}\text { AskNature, Google } \\
\text { Scholar }\end{array}$ \\
\hline $\begin{array}{l}\text { Red sweat of Hip- } \\
\text { popotamus }\end{array}$ & Not identified & $\begin{array}{l}\text { Norhipposudoric } \\
\text { acid: } 511 \mathrm{~nm}, 418 \text {, } \\
271 \mathrm{sh}, 243 \\
\text { hipposudoric acid: } \\
530 \mathrm{~nm}, 411,270 \text {, } \\
240 \text { (Galasso et al. } \\
\text { 2009). }\end{array}$ & $\begin{array}{l}\text { Possible to be chemi- } \\
\text { cally synthesized } \\
\text { (Galasso et al. 2009). }\end{array}$ & Google, AskNature \\
\hline
\end{tabular}




\begin{tabular}{|l|l|l|l|l|}
\hline & SPF & $\begin{array}{l}\text { Wavelength of max- } \\
\text { imum UV absorp- } \\
\text { tion level (nm) }\end{array}$ & $\begin{array}{l}\text { Potential ways for } \\
\text { mass production }\end{array}$ & Search engine \\
\hline $\begin{array}{l}\text { Gadusol compound } \\
\text { from Marine organ- } \\
\text { isms }\end{array}$ & Not identified & $\begin{array}{l}\text { Varies with } \mathrm{pH} \text { value } \\
(\mathrm{pH} 7.0=296 \mathrm{~nm}) \\
\text { (Osborn et al. 2019). }\end{array}$ & $\begin{array}{l}\text { Mix and matched ap- } \\
\text { proach (Osborn et al. } \\
2019) .\end{array}$ & Google \\
\hline $\begin{array}{l}\text { Mucus from mush- } \\
\text { room coral }\end{array}$ & Not identified & $\begin{array}{l}332 \mathrm{~nm} \text { (Drollet et } \\
\text { al. 1993) }\end{array}$ & Not identified & AskNature \\
\hline
\end{tabular}

\section{Discussion}

Due to the thinning of the ozone layer and beauty trends that promote tanning, sunscreen demands have risen sharply during the past few decades. However, Sunscreen remains washed off from beachgoers cause irreversible damages on marine organisms (Tovar-Sánchez et al. 2013). There is therefore a need to replace current unsustainable synthetic UV-filters with natural alternatives that minimize toxicity to mainly marine organisms. Our review focused mainly on plant, microorganism, and animal-based components that were found to have an UV absorbing ability. all identified candidates are found through three search engines: Google, Google scholar, and AskNature. Although, the difference between the number of useful results from the three search engines was not statically significant, Google generated the greatest number of useful hits in the initial search, but AskNature generated more of the most promising suggestions with the highest potential of replacing the current synthetic sunscreens. Google Scholar, however, surprisingly appeared to generate the least amount of useful and related results. This is similar to other studies, where AskNature has for example proven useful in identifying solutions for innovative dry toilets in developing countries (Lenau and Hesselberg 2015) and for developing adaptive leg protheses (Lenau et al. 2010).

From the nine potential natural UV-filters, we again evaluated them based on UV-absorbing ability, toxicity level (if provided), and degradability (if provided), and we selected three solutions that we deemed had the highest potential: nanoparticles of ivy rootlet, lichen extracts, and Gadusol compounds from marine organisms.

The nanoparticles of ivy rootlets were selected these nanonparticles have a better UV absorbing ability across the UV-B region than $\mathrm{TiO} 2$ (one of the most commonly used inorganic synthetic UV-filter), and have a lower toxicity level to human skin than $\mathrm{TiO} 2$ (Xia et al. 2010). They are furthermore degradable when modeled with the human enzymatic digestion process (Xia et al. 2010). Current research conducted on nanoparticles of ivy rootless has discovered a promising harvesting method by growing ivy roots in sterile Magenta GA-7 (MAG) (Lenaghan et al. 2013). Based on findings on its high UV absorbability, low toxicity level, signs of degradability, and potential to be mass produced, we selected it as one of the three final results with the highest potential of becoming a future sunscreen.

Lichen extract, usnic acid, from four Chilean lichens were selected for its high SPF value comparable to a type of Nivea oil spray. An experiment was conducted on volunteers where the SPF value of usnic acid was measured after applying to volunteers' skin. The SPF value of usnic acid is 4.2 (Radice et al. 2016), the highest among all candidates with an identified SPF value. Usnic acid could be commercially synthesized with two steps: the methylation of phloracetophenone, and the oxidation with horseradish peroxidase (Hawranik et al. 2009). With its comparable high SPF value, we have selected it as one of our three most recommended natural UV-filter.

Gadusol compounds from Marine fish were selected for their effective UV absorbing ability that covers the UV-A and UV-B regions, their potential for being mass produced, and their high occurrence rate in organisms that ranges from bacteria to marine vertebrates. The potential of gadusol compounds to become future sunscreens has to some extent already been recognized with the establishment of the company Gadusol Laboratories, devoted to produce 
gadusol based sunscreen ingredients. For all three potential solutions, however, future research and development especially in relation to the SPF value, and the toxicity levels for humans and ecosystems as well as their degradability is urgently needed.

\section{Other potentially useful biologically inspired sunscreen compounds}

Other than the three recommended natural UV-filters with the highest potential (nanoparticles of ivy, lichen extract, and gadusol compounds), red sweat of hippos, natural oils, and melanin are also worth future investigations. The red sweat of hippos is novel but the acids from the red sweat with UV absorbing ability is highly unstable where the potential to be applied on human skin is low compared to the three most recommended ones. Natural oils, however, faced severe controversies where the SPF value is not determined (Ácsová et al. 2021). Tanning or a protection mechanism that results from the production of Melanin is considered as one of the most useful way to reduce UVR damage. However, melanin is not included in our list as it is produced by human, and the UV protective ability of Melanin is confirmed and well known (lewis et al. 2017).

\section{Limitations}

The method that our review used was dependent on existing papers where controversies and inaccuracies may exist. For example as highlighted above, natural oils faced controversies on their SPF values, where the SPF value of raspberry seed oil is 28 in one journal article (cite it here) and 2.6 in another (cite it here). The resulting webpages, journal articles, and strategies that are generated in Google, Google Scholar, and AskNature (especially AskNature) is sensitive to the wording of search terms, so the results might not cover all potentially useful compounds. When the search term entered to AskNature is changed from "protect from UV radiation" to "UV radiation protection" only one from our recommendation list that were previously found with AskNature were generated (Cuticular wax of dwarf mountain pine).

\section{Conclusion}

The goal of developing a natural sustainable sunscreen with high protection factor is still in the premature period with much more research being urgently demanded. Nanoparticles, Lichen extract, and gadusol compound are discovered through Google, Google Scholar, and AskNature by utilizing a biologically inspired design that takes on a sustainability and problem-driven approach (Lenau et al. 2018). Although there are limitations due to the high dependence on existing papers, the BID approach is an efficient way for developing solutions on global problems that seeks for sustainable solutions with Google searches good at generating a wealth of initial ideas, but AskNature searches identifying the most promising ideas.

\section{Acknowledgements}

I would like to express my gratitude to Professor Thomas Hesselberg from Oxford University for editing,suggesting ideas, and offering Dry sanitation concepts with inspiration from nature and Paradigms for biologically inspired design as references. 


\section{References}

Ácsová, A., Hojerová, J., Janotková, L., Bendová, H., Jedličková, L., Hamranová, V. and Martiniaková, S., 2021. The real UVB photoprotective efficacy of vegetable oils: in vitro and in vivo studies. Photochemical \& Photobiological Sciences, 20(1), pp.139-151.

Baker, L.A., Marchetti, B., Karsili, T.N., Stavros, V.G. and Ashfold, M.N., 2017. Photoprotection: extending lessons learned from studying natural sunscreens to the design of artificial sunscreen constituents. Chemical Society Reviews, 46(12), pp.3770-3791.

Downs, C.A., Kramarsky-Winter, E., Segal, R., Fauth, J., Knutson, S., Bronstein, O., Ciner, F.R., Jeger, R., Lichtenfeld, Y., Woodley, C.M. and Pennington, P., 2016. Toxicopathological effects of the sunscreen UV filter, oxybenzone (benzophenone-3), on coral planulae and cultured primary cells and its environmental contamination in Hawaii and the US Virgin Islands. Archives of environmental contamination and toxicology, 70(2), pp.265-288.

Derikvand, P., Llewellyn, C.A. and Purton, S., 2017. Cyanobacterial metabolites as a source of sunscreens and moisturizers: a comparison with current synthetic compounds. European Journal of Phycology, 52(1), pp.43-56.

Drollet, J. H., P. Glaziou, and P. M. V. Martin. "A study of mucus from the solitary coral Fungiafungites (Scleractinia: Fungiidae) in relation to photobiological UV adaptation." Marine Biology 115.2 (1993): 263266.

Dummer, R. and Maier, T., 2002. UV protection and skin cancer. Cancers of the Skin, pp.7-12.

Gago-Ferrero, P., Alonso, M.B., Bertozzi, C.P., Marigo, J., Barbosa, L., Cremer, M., Secchi, E.R., Azevedo, A., Lailson-Brito Jr, J., Torres, J.P. and Malm, O., 2013. First determination of UV filters in marine mammals. Octocrylene levels in Franciscana dolphins. Environmental science \& technology, 47(11), pp.5619-5625.

Gao, Q. and Garcia-Pichel, F., 2011. Microbial ultraviolet sunscreens. Nature Reviews Microbiology, 9(11), pp.791802.

Galasso, V. and Pichierri, F., 2009. Probing the molecular and electronic structure of norhipposudoric and hipposudoric acids from the red sweat of hippopotamus amphibius: a DFT investigation. The Journal of Physical Chemistry A, 113(11), pp.2534-2543.

Hawranik, D.J., Anderson, K.S., Simmonds, R. and Sorensen, J.L., 2009. The chemoenzymatic synthesis of usnic acid. Bioorganic \& medicinal chemistry letters, 19(9), pp.2383-2385.

Jacobs, J.F., Koper, G.J.M. and Ursem, W.N.J., 2007. UV protective coatings: a botanical approach. Progress in organic coatings, 58(2-3), pp.166-171

Kim, S., Jung, D., Kho, Y. and Choi, K., 2014. Effects of benzophenone-3 exposure on endocrine disruption and reproduction of Japanese medaka (Oryzias latipes)—A two generation exposure study. Aquatic toxicology, 155, pp.244-252.

Krupp, David A. "The composition of the mucus from the mushroom coral Fungiascutaria." Proc. 4th Int. Coral Reef Symp. Vol. 2. 1982.

Labille, J., Slomberg, D., Catalano, R., Robert, S., Apers-Tremelo, M.L., Boudenne, J.L., Manasfi, T. and Radakovitch, O., 2020. Assessing UV filter inputs into beach waters during recreational activity: A field study of three French Mediterranean beaches from consumer survey to water analysis. Science of the Total Environment, 706, p.136010.

Lambers, H., Chapin, F.S. and Pons, T.L., 2008. Photosynthesis. In Plant physiological ecology (pp. 11-99). Springer, New York, NY.

Lebedev, A.N., Gartz, M., Kreibig, U. and Stenzel, O., 1999. Optical extinction by spherical particles in an absorbing medium: application to composite absorbing films. The European Physical Journal D-Atomic, Molecular, Optical and Plasma Physics, 6(3), pp.365-373. 
Lenau, T. and Hesselberg, T., 2015. Dry sanitation concepts with inspiration from nature. Journal of Water, Sanitation and Hygiene for Development, 5(2), pp.330-335.

Lenau, T., Dentel, A., Ingvarsdóttir, P. and Guđlaugsson, T., 2010. Engineering design of an adaptive leg prosthesis using biological principles. In DS 60: Proceedings of DESIGN 2010, the 11th International Design Conference, Dubrovnik, Croatia.

Lenau, T.A., Metze, A.L. and Hesselberg, T., 2018, March. Paradigms for biologically inspired design. In Bioinspiration, Biomimetics, and Bioreplication VIII (Vol. 10593, p. 1059302). International Society for Optics and Photonics.

Lenaghan, S.C., Burris, J.N., Chourey, K., Huang, Y., Xia, L., Lady, B., Sharma, R., Pan, C., LeJeune, Z., Foister, S. and Hettich, R.L., 2013. Isolation and chemical analysis of nanoparticles from English ivy (Hedera helix L.). Journal of the Royal Society Interface, 10(87), p.20130392.

Matsui, K., Nazifi, E., Kunita, S., Wada, N., Matsugo, S. and Sakamoto, T., 2011. Novel glycosylated mycosporinelike amino acids with radical scavenging activity from the cyanobacterium Nostoc commune. Journal of Photochemistry and Photobiology B:Biology, 105(1), pp.81-89.

Matsui, K., Nazifi, E., Hirai, Y., Wada, N., Matsugo, S. and Sakamoto, T., 2012. The cyanobacterial UV-absorbing pigment scytonemin displays radical-scavenging activity. The Journal of general and applied microbiology, 58(2), pp.137-144.

Oomah, B.D., Ladet, S., Godfrey, D.V., Liang, J. and Girard, B., 2000. Characteristics of raspberry (Rubus idaeus L.) seed oil. Food chemistry, 69(2), pp.187-193.

Oyamada, C., Kaneniwa, M., Ebitani, K., Murata, M. and Ishihara, K., 2008. Mycosporine-like amino acids extracted from scallop (Patinopecten yessoensis) ovaries: UV protection and growth stimulation activities on human cells. Marine Biotechnology, 10(2), pp.141-150.

Osborn, A.R., Almabruk, K.H., Holzwarth, G., Asamizu, S., LaDu, J., Kean, K.M., Karplus, P.A., Tanguay, R.L., Bakalinsky, A.T. and Mahmud, T., 2015. De novo synthesis of a sunscreen compound in vertebrates. Elife, 4, p.e05919.

Park, H.Y., Kosmadaki, M., Yaar, M. and Gilchrest, B.A., 2009. Cellular mechanisms regulating human melanogenesis. Cellular and Molecular Life Sciences, 66(9), pp.1493-1506.

Radice, M., Manfredini, S., Ziosi, P., Dissette, V., Buso, P., Fallacara, A. and Vertuani, S., 2016. Herbal extracts, lichens and biomolecules as natural photo-protection alternatives to synthetic UV filters. A systematic review. Fitoterapia, 114, pp.144-162.

Ridder, Published by M.; 23, Nov (2020): „Sunscreen cream FORECAST market SIZE Worldwide 2019-2024 . Retrieved am 21.02.2021 from https:/www.statista.com/statistics/866356/sunscreen-ingredients-globalmarket-size-

forecast/\#: :text=The $\% 20$ global $\% 20$ sunscreen $\% 20$ cream $\% 20$ market,billion $\% 20 U . S \% 20$ dollars $\% 20$ by $\% 2$ 02024.

Saikawa, Y., Hashimoto, K., Nakata, M., Yoshihara, M., Nagai, K., Ida, M. and Komiya, T., 2004.The red sweat of the hippopotamus. Nature, 429(6990), pp.363-363.

Shick, J.M. and Dunlap, W.C., 2002. Mycosporine-like amino acids and related gadusols: biosynthesis, accumulation, and UV-protective functions in aquatic organisms. Annual review of Physiology, 64(1), pp.223-262.

Taira, H., Aoki, S., Yamanoha, B. and Taguchi, S., 2004. Daily variation in cellular content of UV-absorbing compounds mycosporine-like amino acids in the marine dinoflagellate Scrippsiella sweeneyae. Journal of Photochemistry and Photobiology B: Biology, 75(3), pp.145-155.

Tovar-Sánchez, A., Sánchez-Quiles, D., Basterretxea, G., Benedé, J.L., Chisvert, A., Salvador, A., Moreno-Garrido, I. and Blasco, J., 2013. Sunscreen products as emerging pollutants to coastal waters. PLoS One, 8(6), p.e65451. 
Xia, L., Lenaghan, S.C., Zhang, M., Zhang, Z. and Li, Q., 2010. Naturally occurring nanoparticles from English ivy: an alternative to metal-based nanoparticles for UV protection. Journal of Nanobiotechnology, 8(1), pp.1-9. 